\title{
The ParlSpeech data set \\ Annotated full-text vectors of 3.9 million plenary speeches in the key legislative chambers of seven European states
}

\author{
CHRISTIAN RAUH \\ WZB Berlin Social Science Center \\ christian.rauh@wzb.eu \\ PIETER DE WILDE \\ NTNU Trondheim \\ pieter.dewilde@ntnu.no \\ JAN SCHWALBACH \\ University of Cologne \\ schwalbach@wiso.uni-koeln.de
}

May 242017

For using any of the described data in parts or in full or for quoting this note, please cite the resource as:

Rauh, Christian, Pieter De Wilde, and Jan Schwalbach (2017) 'The ParlSpeech data set: Annotated full-text vectors of 3.9 million plenary speeches in the key legislative chambers of seven European states', Harvard Dataverse, V1, http://dx.doi.org/10.7910/DVN/E4RSP9.

\section{Acknowledgements}

We are very grateful for the diligent research assistance of Pavel Šatra and Niklas Mäkinen who managed the lion share of scraping and splitting the Czech and Finish debates, respectively. Kris Best provided precious assistance in collecting and cleaning external MP and party lists used for annotation. The work presented here has furthermore benefitted from various research facilities at the WZB Berlin Social Science Center and participation in the Erasmus Academic PADEMIA network, funded by the European Union Lifelong Learning Programme. 


\section{Introduction}

Different strands of the political sciences have recently turned to the (semi-)automated analysis of large text corpora to draw systematic inferences about empirical phenomena (for overviews see Lemke and Wiedemann 2016; Grimmer and Stewart 2013; Cardie and Wilkerson 2008). On the one hand, this is driven by the fact that political behaviour often finds expression in and through some form of text. In modern democracies, especially parliamentary debates are a key arena for representative claims-making, partisan competition and deliberation about political alternatives (De Wilde 2013; Proksch and Slapin 2010; Quinn et al. 2010; Klemmensen et al. 2007). On the other hand, text-based inferences on the priorities and positions of political actors have become much more tangible for applied research. Digital access to relevant sources has increased while manageable software tools proliferate. ${ }^{1}$ However, bringing the often only rather loosely structured text sources into a format that is amenable to automated analysis still presents a major hurdle. Collecting, cleaning and annotating relevant corpora can quickly consume the time and resources available in typical applied research projects (for an introduction to relevant techniques, see Munzert et al. 2015).

Against this background we aim to contribute to the public availability of annotated full-text vectors that offer relevant empirical information for a broad range of political science research questions (for similar efforts see Merz et al. 2016; Schumacher et al. 2016). With this note we thus release annotated full-text vectors of more than 3.9 million plenary speeches in the key legislative chambers of the Czech Republic, Finland, Germany, the Netherlands, Spain, Sweden, and the United Kingdom, covering periods between 22 and 28 years.

The speech data presented here were initially collected for a project studying the partisan salience of EU affairs in domestic plenary debates (cf. Rauh and Wilde 2017; Schwalbach 2017; Rauh 2015). This particular research interest drives the selection of countries and partially also the time periods covered. But the amount of speeches as well as the broad geographical and temporal coverage should also prove useful for other research projects on questions of representation, partisan politics or political text analysis more generally. ${ }^{2}$

The remainder of this note aims at allowing interested researchers a quick assessment of the provided resources. Section 2 briefly describes the scraping and splitting routines by which the speeches were collected and assembled into the corpora. Section 3 provides a guide to the individual files, lists the contained variables and briefly discusses the vectors of speech texts.

\footnotetext{
1 See, for example, https://cran.r-project.org/web/views/NaturalLanguageProcessing.html (last accessed: 28.04.2017)

${ }^{2}$ Comparative analysis of such corpora is furthermore facilitated by automated translation procedures (De Vries et al. 2017; Lucas et al. 2015).
} 


\section{Data collection}

Having selected relevant countries along our original research goals (see above), data collection focussed on the domestic parliamentary chamber with most competences in legislation and government formation. In result, the ParlSpeech data set covers the Czech Poslanecká snèmovna Parlamentu, the Dutch Tweede Kammer, the Finnish Eduskunta, the German Bundestag, the Spanish Congreso de los Disputados, the Swedish Riksdag, as well as the UK House of Commons.

For each of these parliaments we identified the most encompassing database that provides digital full-text access to the plenary debates in the respective chamber. These online sources were then scraped with own R scripts customized to the structures and formats of the respective database. Afterwards, a second set of scripts - again customized to the specific formats supplied automatically cleans the downloaded material, splits it into individual speeches, and annotates the resulting observations with the speaker's name, his or her party membership and/or specific parliamentary roles, identifiers of legislative sessions, a running speech number within the session, as well as various time stamps.

For the Czech Poslanecká snèmovna Parlamentu we scraped html versions of the plenary protocols from the documentation website of the Chamber of Deputies. ${ }^{3}$ Before splitting and cleaning them, the raw html files were externally converted to UTF-8 encoding. Speaker and party annotation rested on external list generated by scraping the individual sub pages of Czech MPs.

The speech data for the Finnish case were scraped by a native speaker as pdf files from the website of the Eduskunta. ${ }^{4}$ These were first automatically cropped to remove boilerplate in headers and footers and then batch-converted to plain UTF-8 txt files with an external software. Splitting and annotation then resorted to formatting regularities in the source material.

We scraped the plenary protocols of the German Bundestag as plain txt or asc files from the parliament's document server ${ }^{5}$ and then used a set of regular expressions as well as external MP lists to split the stenographic debate protocols along formatting regularities observed in the textual structure.

\footnotetext{
${ }^{3}$ http://www.psp.cz/eknih/index.htm (last accessed: 11.05.2016).

${ }^{4}$ https://www.eduskunta.fi/FI/search/Sivut/vaskiresults.aspx?k $=$ (last accessed: 27.03 .2016 )

${ }^{5}$ http://dipbt.bundestag.de/doc/btp (last accessed: 25.05.2014). We have been made aware that the structure of the Bundestag website has significantly changed after our scraping efforts. However, a full copy of the original raw text files is available from the first author of this note.
} 
The Spanish data were scraped from the website of the Congreso ${ }^{6}$ where they are only available as pdf files. We converted them with external software to txt and conducted systematic manual cleaning of OCR errors where necessary, before splitting the files also along formatting regularities.

The Swedish plenary protocols were accessed via the website of the Sveriges Riksdag. Besides various other documents the website provides all parliamentary debates since 1971 in different file formats, such as txt or html. Due to the clear and user-friendly structure of these files, cleaning and splitting them into individual speeches was comparatively straightforward.

Parliamentary records from the Tweede Kamer, at least after 1994, were accessed as already very well-structured $\mathrm{xml}$ files provided through the central online access point of the Dutch government. ${ }^{8}$ Parsing and annotation relied on the provided xml tags.

Finally, the House of Commons debates were accessed via the digital Commons Hansard. ${ }^{9}$ Besides variation in URL structures over time, a particular challenge of this database are debates stretching over an a priori unknown number of sub-pages. Splitting and cleaning, in contrast, was comparatively easy along the given html structure that has only rarely changed over time.

All these procedures were implemented in the $\mathrm{R}$ environment ( $\mathrm{R}$ Development Core Team 2008), resorting mainly to the base text processing capabilities ${ }^{10}$ as well as to the stringr (Wickham 2015), RCurl (Lang and R Core Team 2016), doParallel (Revolution Analytics and Weston 2015) and XML (Lang and R Core Team 2015) packages. During development of the scripts we extensively discussed key steps and specific challenges in the whole research team. Adapting the scripts to each individual data source involved an intense back-and-forth and various crosschecks between the online resources and the raw texts on the one hand and the resulting data frames on the other. Finally, a range of random sample debate comparisons per country verified that raw debate protocols and text vectors are identical with regard to speech content and speaker characteristics.

\footnotetext{
${ }^{6}$ www.congreso.es/portal/page/portal/Congreso/Congreso/Publicaciones (last accessed 17.12.2015).

7 http://data.riksdagen.se/data/dokument/ (last accessed 01.05.2017)

8 zoek.officielebekendmakingen.nl (last accessed: 14.12.2015). With a country specialist we pre-selected only those items that contain political debates on the floor, excluding, e.g., practical announcements by the President of Parliament ('Mededelingen'), order of the agenda and planning of activities ('Regeling van werkzaamheden'), celebrations and commemorations ('Beëdiging(en) van', 'Afscheid', 'Herdenking') or closure ceremonies ('Sluiting').

${ }^{9}$ www.parliament.uk/business/publications/hansard/commons/by-date (last accessed: 22.01.2016)

${ }^{10}$ https://en.wikibooks.org/wiki/R Programming/Text Processing (last accessed: 28.04.2017)
} 


\section{Data description}

\subsection{Corpora and speech availability}

We stored the resulting speech vectors into one corpus per parliamentary chamber. Table 1 below provides an overview of the data frames in the ParlSpeech dataverse. First it should be noted that periods for which full text is available varies in the scraped data sources. Thus, start and end point of the covered period differs slightly over the seven parliaments. Rather than harmonising the investigation period we opted to publish as many speeches as could be fetched along the above described procedures. ${ }^{11}$ Within these temporal constraints, however, the provided text vectors represent a census of plenary debate in the given parliament. Of course, we cannot completely rule out technical errors in the original database sources. Yet, during numerous random sample checks and visual analyses of the temporal speech distributions (Figure 1 below) we did not find any unusual breaks except for typical low periods during summer, Christmas and government formation.

Second, the reader should note cross-national variation in the number of available speeches. This is partially driven by the number of parties in Parliament, but can be mainly explained by different parliamentary traditions and operations. While the ideal-typical 'talking parliament' in the UK handles most of its business through many speeches on the plenary floor, most of the policy work in 'working parliaments' such as the German Bundestag happens in committees while the plenary floor is reserved to fewer and also longer speeches. One technical nuisance has to be noted in this regard, however. While the $\mathrm{HoC}$ protocols treat interventions and interruptions from the floor as separate speech acts, similar actions are hidden within the text of the main speaker in the German Bundestag (and were removed in the original data collection by Rauh 2015). Whether this matters in applied research depends on the particular research question. In our own substantial applications, for example, we successfully filtered out HoC interruptions by removing speeches containing less than ten terms.

\subsection{Variables}

All seven corpora have an identical structure with nine variables derived from the automated annotation procedures described above. The variable date stores the day of speech delivery in a character vector (YYYY-MM-DD). For researchers interested in particular debates, session stores

\footnotetext{
${ }^{11}$ For the Tweede Kamer and the House of Commons older records exist, but are supplied in different database and different formats. Setting up corresponding scraping and splitting scripts, however, exceeded the resources and the purposes of our substantial research project.
} 
the debate number following the conventions of the respective parliament. ${ }^{12}$ For researchers wishing to study interaction patterns, the variable speechnumber stores the running order of speeches within session. Along this variable, the original temporal order of a particular debate can be restored.

The column speaker holds the name of the person having given the speech as provided in the official protocol or other parliamentary sources. Researchers wishing to exploit this variable to match individual level data should take into account that speaker names might slightly diverge from external lists with regard to nicknames, middle initials or titles. ${ }^{13}$

The variable party indicates the partisan faction ${ }^{14}$ of the speaker as given in the plenary protocol. We have already harmonized slight temporal differences in the protocols' references to the same party. ${ }^{15}$ Researchers wishing to match party-level data along this variable should note the party names in our data (listed in the final column of Table 1) do not necessarily match external sources such as the Chappel Hill Expert survey (Bakker et al. 2015), the Manifesto Data (Volkens et al. 2014), or the ParlGov database (Döring and Manow 2015). However, party names can be easily harmonized by exploiting the R's sub() functions.

The variable chair is a simple dummy storing whether the speech was given by the contemporaneously acting chairman of the respective parliament or his/her step-ins. This is for example useful if a research project aims to reduce noise by ignoring these speeches that virtually always serve for debate organisations only. ${ }^{16}$

For some purposes, speech length might be a useful filter as well. Thus the variable terms stores the overall length of the speech string simply operationalized as number of whitespaces plus one.

Finally, the variable text stores the raw text of the speech as given in the original plenary protocol. These character vectors are encoded in UTF-8. Apart from removing boilerplate such as headers, footers or page numbers, the data cleaning procedures have changed the original debate text as little as possible. Storing the full text of speeches in partially rather long strings results in rather

\footnotetext{
${ }^{12}$ For the Dutch case the original source files contain session number from January 12011 onwards only. Similarly, no session number can be retrieved from the Swedish Riksdag protocols. Thus we set session equal to date in these two corpora.

13 The HoC debates pose one particular challenge in this regard. If a speaker appears several times in a debate, he/she is only referred to be his/her last name in subsequent speeches. In the data we publish here this problem is already solved, however. Based on external MP lists we set up an algorithm that looks backwards and fills in the full name of speakers appearing twice or more often within a session.

${ }^{14}$ In the German case, CDU and CSU form one faction. Researchers wishing to distinguish these two parties should recode the party variable along external MP lists.

${ }^{15}$ As, for example, with regard to the German 'PDS/LINKE' which has also figured as "Die Linke", "LINKE" or "PDS", respectively.

16 This information is missing for the Eduskunta. Matching this function from external lists via speaker names is required in this case.
} 
large files, but is driven by the desire to allow other researchers as much methodological choice as possible. On the one hand, text pre-processing can have drastic effects on the conclusions drawn from bags-of-word models (Greene et al. 2016; Denny and Spirling 2017). On the other hand, advanced natural language processing tools frequently resort to the grammatical structure of the original text (e.g. Van Atteveldt et al. 2008). Thus, providing 'raw' texts in tabular format seems the most flexible way forward. From this point of departure modern $\mathrm{R}$ packages such as tm (Feinerer and Hornik 2014), quanteda (Benoit and Nulty 2015), or koRpus (Michalke 2016) provide handy wrappers to easily create the text and term representations needed for different analytical approaches.

Table 1 summarizes the available data frames while Figure 1 plots the temporal distribution of available full-text per parliamentary chamber. We sincerely hope that these data stimulate further text-based research in questions of representation, party politics and political language more generally. In any case we would be very happy to hear about your projects using these data. 


\begin{tabular}{|c|c|c|c|c|c|c|c|c|c|}
\hline Parliament & Corpus File (.Rdata) & $\begin{array}{l}\text { Size } \\
(\mathrm{MB})\end{array}$ & Period & $\begin{array}{l}\text { Speeches } \\
\text { in corpus }\end{array}$ & $\begin{array}{l}\text { Av. } \\
\text { speeches } \\
\text { /month }\end{array}$ & $\begin{array}{l}\text { Av. terms } \\
\text { per speech } \\
\text { (w/out } \\
\text { chair) }\end{array}$ & $\begin{array}{l}\text { Unique } \\
\text { terms in } \\
\text { corpus }\end{array}$ & $\begin{array}{l}\text { Unique } \\
\text { speakers }\end{array}$ & Unique parties \\
\hline $\begin{array}{l}\text { CZ: } \\
\text { Poslanecká } \\
\text { sněmovna } \\
\text { Parlamentu }\end{array}$ & Corp_PSP & 105 & $\begin{array}{l}1993 / 01 \\
2016 / 06\end{array}$ & 329,135 & 1286 & $\begin{array}{c}157.2 \\
(240.4)\end{array}$ & 272,744 & 1096 & $\begin{array}{l}\text { ANO, ČMSS, ČMUS, ČSSD, HSD-SMS, } \\
\text { HSDMS, KDS, KDU-ČSL, KSČM, LB, } \\
\text { LSNS, LSU, Nez.-SZ, Nezařazení, } \\
\text { ODA, ODS, ONH, other, SPR-RSČ, } \\
\text { SZ, TOP09, US, US-DEU, Úsvit, VV }\end{array}$ \\
\hline $\begin{array}{l}\text { DE: } \\
\text { Bundestag }\end{array}$ & Corp_Bundestag & 191 & $\begin{array}{l}1991 / 03 \\
2013 / 09\end{array}$ & 299,844 & 1219 & $\begin{array}{c}314.7 \\
(495.8)\end{array}$ & 608,637 & 1846 & $\begin{array}{l}\text { CDU/CSU, FDP, GRUENE, other, } \\
\text { PDS/LINKE, SPD }\end{array}$ \\
\hline $\begin{array}{l}\text { ES: } \\
\text { Congresso }\end{array}$ & Corp_Congresso & 142 & $\begin{array}{l}1989 / 11 \\
2015 / 10\end{array}$ & 290,680 & 1135 & $\begin{array}{c}256.2 \\
(526.9)\end{array}$ & 744,922 & 2053 & $\begin{array}{l}\text { CC, CDS, CHA, CiU, ERC, IP, IU, IU- } \\
\text { ICV, other, PA, PNV, PP, PSOE, UPyD }\end{array}$ \\
\hline $\begin{array}{l}\text { FI: } \\
\text { Eduskunta }\end{array}$ & Corp_Eduskundta & 161 & $\begin{array}{l}1991 / 04 \\
2015 / 12\end{array}$ & 245,852 & 1083 & $\begin{array}{c}233.5 \\
(-)\end{array}$ & $1,745,689$ & 793 & $\begin{array}{l}\text { AlkioistCentristGroup, } \\
\text { GroupAlkiolainen, GroupPuhjo, } \\
\text { GroupVirtanen, KD/SKL, Kesk, Kok, } \\
\text { LKP, M11, NUOR, other, PS, } \\
\text { Remonttiryhmä, RKP, SDP, SMP, va-r, } \\
\text { Vas, Vihreät, Vr }\end{array}$ \\
\hline $\begin{array}{l}\text { NL: } \\
\text { Tweede Kamer }\end{array}$ & Corp_TweedeKamer & 228 & $\begin{array}{l}1994 / 12 \\
2015 / 11\end{array}$ & 900,796 & 3882 & $\begin{array}{c}149.1 \\
(165.6)\end{array}$ & 733,632 & 870 & $\begin{array}{l}\text { SP, PvdA, GL, D66, GPV, VVD, CDA, } \\
\text { other, RPF, SGP, LPF, PVV, PvdD, CU }\end{array}$ \\
\hline $\begin{array}{l}\text { SE: } \\
\text { Riksdag }\end{array}$ & Corp_Riksdag & 227 & $\begin{array}{l}1990 / 10 \\
2015 / 12\end{array}$ & 318,769 & 1250 & $\begin{array}{c}355.2 \\
(356.4)\end{array}$ & 988,280 & 2142 & $\begin{array}{l}\text { C, FP, KD, M, MP, NYD, other, S, SD, } \\
\text { V }\end{array}$ \\
\hline $\begin{array}{l}\text { UK: } \\
\text { House of } \\
\text { Commons }\end{array}$ & $\begin{array}{l}\text { Corp_HouseOfComm } \\
\text { ons }\end{array}$ & 565 & $\begin{array}{l}1988 / 11 \\
2015 / 01\end{array}$ & $1,540,065$ & 5641 & $\begin{array}{c}195.0 \\
(202.1)\end{array}$ & $1,037,204$ & 1994 & $\begin{array}{l}\text { APNI, Con, GPEW, Lab, LibDem, } \\
\text { SNP, SDLP, SDP, DUP, other, } \\
\text { PlaidCymru, Referendum, Respect, } \\
\text { UKIP, UKUP, UPUP, UUP }\end{array}$ \\
\hline
\end{tabular}

Table 1: Overview of the ParlSpeech resource 


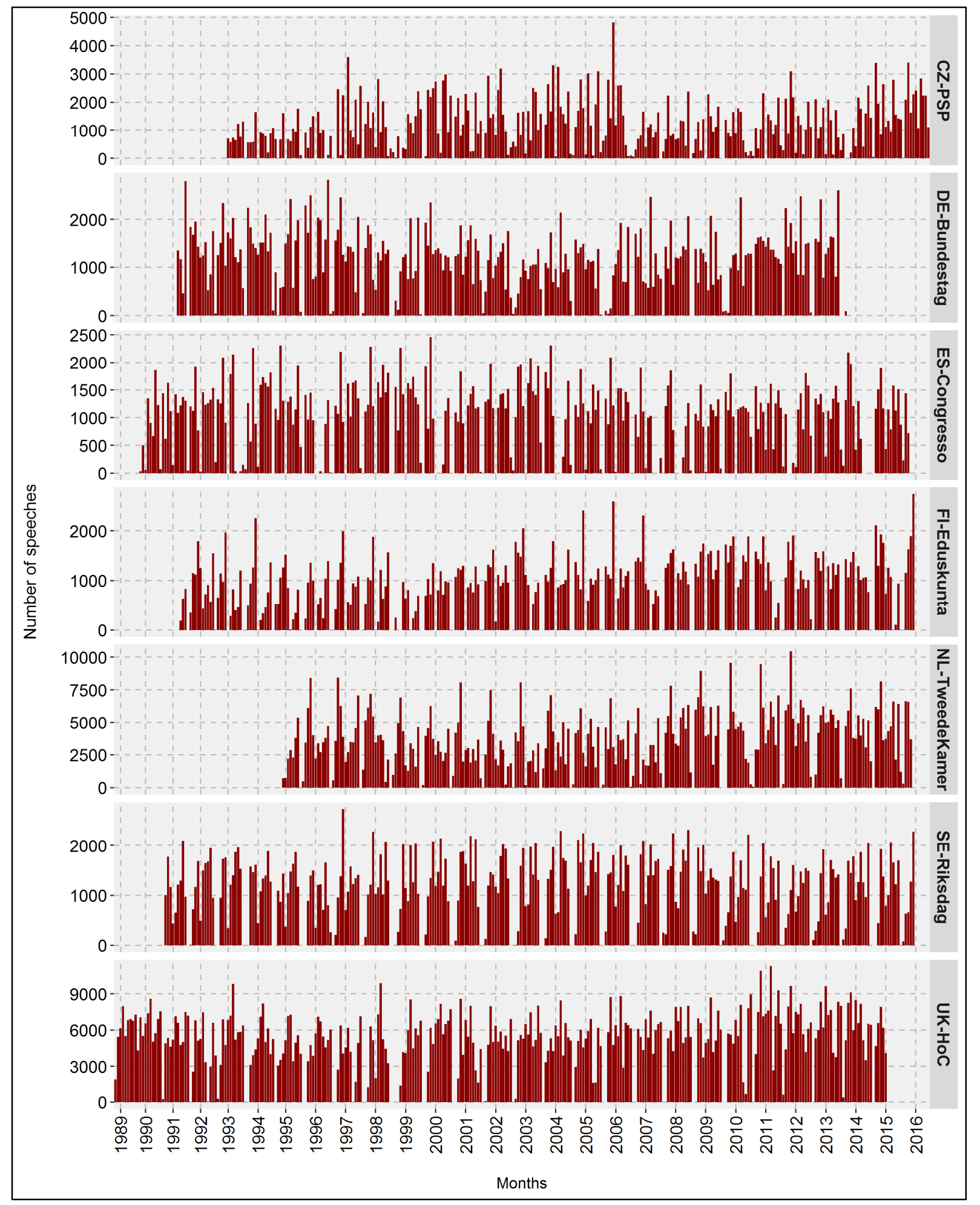

Figure 1: Temporal Distribution of available speeches per parliamentary chamber 


\section{References}

Bakker, Ryan, Catherine de Vries, Erica Edwards, Liesbet Hooghe, Seth Jolly, Gary Marks, Jonathan Polk, Jan Rovny, Marco Steenbergen, and Milada Vachudova (2015) 'Measuring party positions in Europe: The Chapel Hill expert survey trend file, 1999-2010', Party Politics 21(1): 143-152.

Benoit, Kenneth, and Paul Nulty (2015) 'quanteda: Quantitative Analysis of Textual Data. R package version 0.7.2-1'. [cited 11.05.2017]. Available from http://CRAN.Rproject.org $/$ package $=$ quanteda.

Cardie, Claire, and John Wilkerson (2008) 'Text Annotation for Political Science Research', Journal of Information Technology \& Politics 5(1): 1-6.

De Vries, Erik, Martijn Schoonvelde, and Gijs Schumacher (2017) 'Lost in Translation? Evaluating the Usefulness of Machine Translation for Bag-of-words Text Models', Open Science Framework. April 26(osf.io/cuxha).

De Wilde, Pieter (2013) 'Representative claims analysis: theory meets method', Journal of European Public Policy: 278-294.

Denny, Matthew James, and Arthur Spirling (2017) 'Text Preprocessing For Unsupervised Learning: Why It Matters, When It Misleads, And What To Do About It' SSRN. [cited 25.01.2017]. Available from https://ssrn.com/abstract $=2849145$.

Döring, Holger, and Philip Manow (2015) 'Parliaments and governments database (ParlGov): Information on parties, elections and cabinets in modern democracies. Stable version 2015 - 12 March 2016'. [cited. Available from www.parlgov.org

Feinerer, Ingo, and Kurt Hornik (2014) 'tm: Text Mining Package. R package version 0.6.'. [cited 11.05.2017]. Available from http://CRAN.R-project.org/package $=\mathrm{tm}$.

Greene, Zac, Andrea Ceron, Gijs Schumacher, and Zoltan Fazekas (2016) 'The Nuts and Bolts of Automated Text Analysis. Comparing Different Document Pre-processing Techniques in Four Countries', Open Science Framework November 1(osf.io/ghxj8).

Grimmer, Justin, and Brandon Stewart (2013) 'Text as Data: The Promise and Pitfalls of Automatic Content Analysis Methods for Political Texts', Political Analysis 21(3): 267-297.

Klemmensen, Robert, Sara Binzer Hobolt, and Martin Ejnar Hansen (2007) 'Estimating policy positions using political texts: An evaluation of the Wordscores approach', Electoral Studies 26(4): 746-755.

Lang, Duncan Temple, and CRAN Team (2015) 'XML: Tools for Parsing and Generating XML Within R and S-Plus. R package version 3.98-1.3. '.[cited 11.05.2017]. Available from https:/ /CRAN.R-project.org/package=XML.

Lang, Duncan Temple, and CRAN team (2016) 'RCurl: General Network (HTTP/FTP/...) Client Interface for R. R package version 1.95-4.8. '.[cited 11.05.2017]. Available from https://CRAN.R-project.org/package=RCurl.

Lemke, Matthias, and Gregor Wiedemann (2016) Text Mining in den Sozialwissenschaften. Grundlagen und Anwendungen zwischen qualitativer und quantitativer Diskursanalyse. Wiesbaden: Springer VS.

Lucas, Christopher, Richard Nielsen, Margaret Roberts, Brandon Stewart, Alex Storer, and Dustin Tingley (2015) 'Computer-Assisted Text Analysis for Comparative Politics', Political Analysis 23(2): 254-277. 
Merz, Nicolas, Sven Regel, and Jirka Lewandowski (2016) 'The Manifesto Corpus: A new resource for research on political parties and quantitative text analysis', Research \& Politics 3(2): 2053168016643346.

Michalke, Meik (2016) 'koRpus: An R Package for Text Analysis (Version 0.06-4)'.[cited 11.05.2017]. Available from http:// reaktanz.de/?c=hacking\&s=koRpus.

Munzert, Simon, Christian Rubba, Peter Meißner, and Dominic Nyhuis (2015) Automated Data Collection with R: A Practical Guide to Web Scraping and Text Mining. Wiley.

Proksch, Sven-Oliver, and Jonathan B. Slapin (2010) 'Position Taking in European Parliament Speeches', British Journal of Political Science 40(3): 587-611.

Quinn, Kevin, Burt Monroe, Michael Colaresi, Michael Crespin, and Dragomir Radev (2010) 'How to Analyze Political Attention with Minimal Assumptions and Costs', American Journal of Political Science 54(1): 209-228.

R Development Core Team (2008) R: A language and environment for statistical computing. Vienna, Austria: R Foundation for Statistical Computing.

Rauh, Christian (2015) 'Communicating supranational governance? The salience of EU affairs in the German Bundestag, 1991-2013', European Union Politics 16(1): 116-138.

Rauh, Christian, and Pieter De Wilde (2017) 'The Opposition Deficit in EU Accountability: Evidence from over 20 years of plenary debate in four member states', European Journal of Political Research forthcoming.

Revolution Analytics, and Steve Weston (2015) 'doParallel: Foreach Parallel Adaptor for the 'parallel' R package version 1.0.10.'.[cited 11.05.2017]. Available from https://CRAN.Rproject.org $/$ package $=$ doParallel.

Schumacher, Gijs, Martijn Schoonvelde, Denise Traber, Tanushree Dahiya, and Erik de Vries (2016) 'EUSpeech: a New Dataset of EU Elite Speeches', Proceedings of the International Conference on the Advances in Computational Analysis of Political Text.

Schwalbach, Jan (2017) Vom Verlierer zum Mitgestalter? Die Beschäftigung nationaler Parlamente mit der europäischen Integration seit 1990/91., Fachbereich Sozialwissenschaften, Universität Bremen, Bremen.

Van Atteveldt, Wouter, Jan Kleinnijenhuis, and Nel Ruigrok (2008) 'Parsing, Semantic Networks, and Political Authority Using Syntactic Analysis to Extract Semantic Relations from Dutch Newspaper Articles', Political Analysis 16(4): 428-446.

Volkens, Andrea, Pola Lehmann, Nicolas Merz, Sven Regel, Annika Werner, Onawa Promise Lacewell, and Henrike Schultze. 2014. The Manifesto Data Collection. Manifesto Project (MRG/CMP/MARPOR). Berlin: Wissenschaftszentrum Berlin für Sozialforschung (WZB)

Wickham, Hadley (2015) 'stringr: Simple, Consistent Wrappers for Common String Operations. R package version 1.0.0.'. [cited 11.05.2017]. Available from https://CRAN.Rproject.org $/$ package $=$ stringr. 